
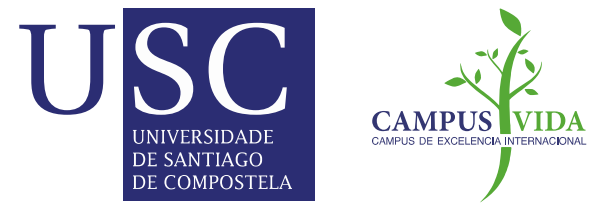

\title{
Integrated evaluation of wine lees valorization to produce value-added products
}

Antonio Cortés, Maria Teresa Moreira, Gumersindo Feijoo

\section{Accepted Mansucript}

\section{How to cite:}

Cortés, A., Moreira, M., \& Feijoo, G. (2019). Integrated evaluation of wine lees valorization to produce value-added products. Waste Management, 95, 70-77. doi: 10.1016/j.wasman.2019.05.056

\section{Copyright information:}

(C) 2019 Elsevier Ltd. This manuscript version is made available under the CC-BY-NC-ND 4.0 license (http://creativecommons.org/licenses/by-nc-nd/4.0/) 


\section{Integrated evaluation of wine lees valorization to produce value-added products}

Antonio Cortés $^{\mathrm{a}^{*},}$, Maria Teresa Moreira ${ }^{\mathrm{a}}$ and Gumersindo Feijoo ${ }^{\mathrm{a}}$

${ }^{a}$ Department of Chemical Engineering, School of Engineering, Universidade de Santiago de Compostela, Rúa Lope Gómez de Marzoa, s/n, 15782 Santiago de Compostela (Spain)

${ }^{*}$ Corresponding author

\section{E-mail: antoniojose.cortes.montoya@usc.es}

\section{Abstract}

The integrated evaluation of the valorization of wine lees to produce value-added products was carried out in this study from a life-cycle perspective. The consumption of steam has been demonstrated as the main hot spot, reaching $85.7 \%$ of the impact on Fossil Depletion and 85.3\% on Climate Change. Bearing in mind that four different value-added products are produced, a sensitivity analysis was carried out in order to ascertain the influence of the functional unit and the allocation method on the environmental outcomes. The performance of this system was compared to other processes that produce antioxidants from different raw materials. These processes were phycocyanin recovery from Spirulina platensis cyanobacterium, the production of the red antioxidant astaxanthin by microalgae and the valorization of the macroalgae Sargassum muticum. Wine lees valorization showed a better environmental profile throughout the entire life cycle, due to the fact that most of the operations performed are physical (solid/liquid separations, distillations, evaporations, etc.) and do not involve a large consumption of electricity or chemicals. However, there is still room for improvement, and future research should focus on optimizing the extraction of antioxidants from wine lees using two-stages aqueous systems, ultrasonic or microwave 
25 assisted extraction, in the pursuit of better performance and lower environmental

26 impact.

27 Keywords: Wine lees valorization; Biorefinery; Life Cycle Inventory; Environmental 28 assessment; Value-added products.

29 Abbreviations

LCA Life Cycle Assessment

LCI Life Cycle Inventory

FU Functional Unit

SS Subsystem

ISO International Organization for Standardization

CC Climate Change

OD Ozone Layer Depletion

TA Terrestrial Acidification

FE Freshwater Eutrophication

ME Marine Eutrophication

HT Human Toxicity

POF Photochemical Oxidant Formation

TET Terrestrial Ecotoxicity

FET Freshwater Ecotoxicity

MET Marine Ecotoxicity

FD Fossil Depletion 


\section{Introduction}

The primary sector is one of the largest industrial sectors in terms of resources and energy consumption (Roy et al., 2009) and has therefore been identified as one of the main actors in climate change, with 30\% of total greenhouse gas (GHG) emissions. With the aim of developing a competitive low-carbon economy (European Comission, 2011), action plans and measures have been put forward to reduce the current level of GHG emissions throughout the food supply chain.

Beyond environmental indicators related to climate change, the low efficiency in food production and processing has been recognized as a major issue. According to a recent FAO report (FAO, 2011), up to 33\% of the food produced for human consumption is lost or wasted along the supply chain. Not only is food wasted, but the resources needed to produce it, such as water, energy, chemicals or fuels used, are also misused, representing a value of nearly 1.3 billion tons per year. In addition, according to data estimated by United Nations (2017), in relation to population growth, world's population is expected to increase to 8.6 billion by 2030, which will probably aggravate the problem of food waste.

Biorefinery is a clear example of the change of paradigm in the framework of sustainable development. Biorefineries represent the transition from oil refineries to sustainable systems based on the valorisation of waste flows with the aim of producing value-added compounds such as biogas, electricity, chemical products or biomaterials (Cherubini, 2010). Following this principle, food waste can be valorised through different technologies, such as anaerobic digestion to generate bio-hydrogen and biomethane (Algapani et al., 2019), co-composting with other types of organic waste for the production of bioenergy and fertilizers (Vico et al., 2018), conversion into animal 
feed (Makkar, 2018) or recovery of sugars, organic acids, pigments, fibre, proteins, oils,

57 antioxidants and vitamins from food waste (García-Herrera et al., 2010).

Within the primary sector, wine production is becoming increasingly important as a symbol of a quality product, with a growing influence on exports from producing countries. World wine production is dominated by Italy, France and Spain, which together account for $48 \%$ of total production (OIV, 2018). From this perspective, the wine sector can be considered a reference point in the EU strategy within the primary production sector (Christ and Burritt, 2013). The winemaking process comprises a numerous sequence of activities (Escribano-Viana et al., 2018), from the cultivation of the vine, the harvest, the process of fermentation and maturation of the wine in the winery to the management of waste generated at each stage of the process. The main effluents from the wine sector are wastewater and organic solid waste (Ruggieri et al., 2009). Solid organic waste includes wine lees and grape pomace, which is composed of stalks, skins and seeds. In general, the volume of waste generated is around $20-30 \%$ of total wine production, which can be considered a meaningful percentage (Zabaniotou et al., 2018).

In order to improve the overall efficiency and environmental impact of the winemaking process, actions have been identified that allow for the minimization, management and effective recovery of waste streams from a circular economy perspective (Musee et al., 2007). The approach of circular economy grants and consolidates the value of each element of the productive chain and deepens the awareness of action, essential to achieve a real change towards sustainability, with efficient use of resources and valorization of by-products and wastes. 
In this framework, Gullón et al. (2018) analysed the environmental impacts of different routes for the valorisation of vine shoots. Poveda et al. (2018) proposed revaluing the by-products of winemaking, grape pomace and stems as a source of natural preservatives. Nayak et al. (2018) developed a method for recovering polyphenols from exhausted grape pomace through activated carbon. Zhang et al. (2017) compared two methods for the valorisation of grape pomace, which is the major component of wine production waste, to add value to economic and environmental balance of the overall process. These processes were combustion to produce electricity, and pyrolysis to produce bio-gas, bio-oil and bio-char. The detailed analysis of the wine lees fraction presents high concentrations of macronutrients and polyphenols and low concentrations of micronutrients and heavy metals (Devesa-Rey et al., 2011). Moreover, the presence of other compounds of potential interest such as polyphenols and antioxidants identifies this stream as an ideal candidate to be valorized (Dimou et al., 2015; Kopsahelis et al., 2018; Martinez et al., 2016).

These valorization options can be evaluated according to their environmental performance. Several environmental assessment methods can be found in literature, as material flow analysis, energy balance, exergy analysis and life cycle assessment (Vandermeersch et al., 2014). The latter seems to be the best choice since it can consider the full life cycle (cradle-to-gate or cradle-to-grave).

The objective of this work seeks to delve into the different strategies for valuing winemaking-derived waste, proposing the identification of critical points in the environmental profile of the process under study, prior to its development and marketing of the products obtained. The function of the system under study is the use of wine lees to produce some bio-based products with marketable added value. It is therefore a question of identifying the most suitable process alternatives in a system 
under development, which may suffer from limitations in terms of data availability, but it may also make it possible to establish a roadmap in the search for viable options from a techno-economic and environmental point of view.

\section{Materials and methods}

\subsection{Definition of scope and system boundaries}

The functional unit is a measure of the function of the system studied and provides a reference to which the inputs and outputs can be related (ISO 14040; 14044). The selection of the functional unit in biorefinery studies is made on the basis of three possible options, i.e. total flow of raw materials, quantity of a single target product or the combination of products (Khoshnevisan et al., 2018). The FU considered in this study was 1 tonne of wine lees processed in the winery facility. This feedstock-based FU is consistent with the choice of other similar studies, in which a similar FU was chosen because of their multiple-output nature (Lam et al., 2018; Vaskan et al., 2018). The production plan was evaluated considering all the processes from the production of raw materials to the final products obtained from the wine lees, in such a way that the processes in the winery are analyzed, mainly those associated with the production of raw materials, electricity, fertilizers, chemical products and water, as well as the consumption of fuel used in the transport of materials.

The foreground system includes process units that are the direct object of the study. This system is divided into two subsystems represented in Figure 1: SS1. Wine production and SS2. Processing plant. Figure 1 shows the block diagram of the process, identifying the system boundaries, the subsystems considered, and the main inputs and outputs. No infrastructure process was considered in the study since the environmental impacts of construction, installation, etc. have been considered negligible during the 
useful life of the facility. This assumption is a common practice in other life cycle assessment studies of different biorefineries (Jeswani et al., 2015; Karlsson et al., 2014). As far as storage processes, it was considered unnecessary in this study, since only a small warehouse within the facilities is needed to store the wine lees at room temperature, so it is included within the infrastructure processes.

Subsystem 1 is divided into two sections: SS1.1. Viticulture comprises different activities considered in the agricultural phase of wine production, including fertilization, field operations or soil management and SS1.2. Vinification includes the processing of grapes in the winery: wine production, bottling and packaging (Vázquez-Rowe et al., 2012). Wine lees are a residue generated during this process, which is further processed in Subsystem 2.

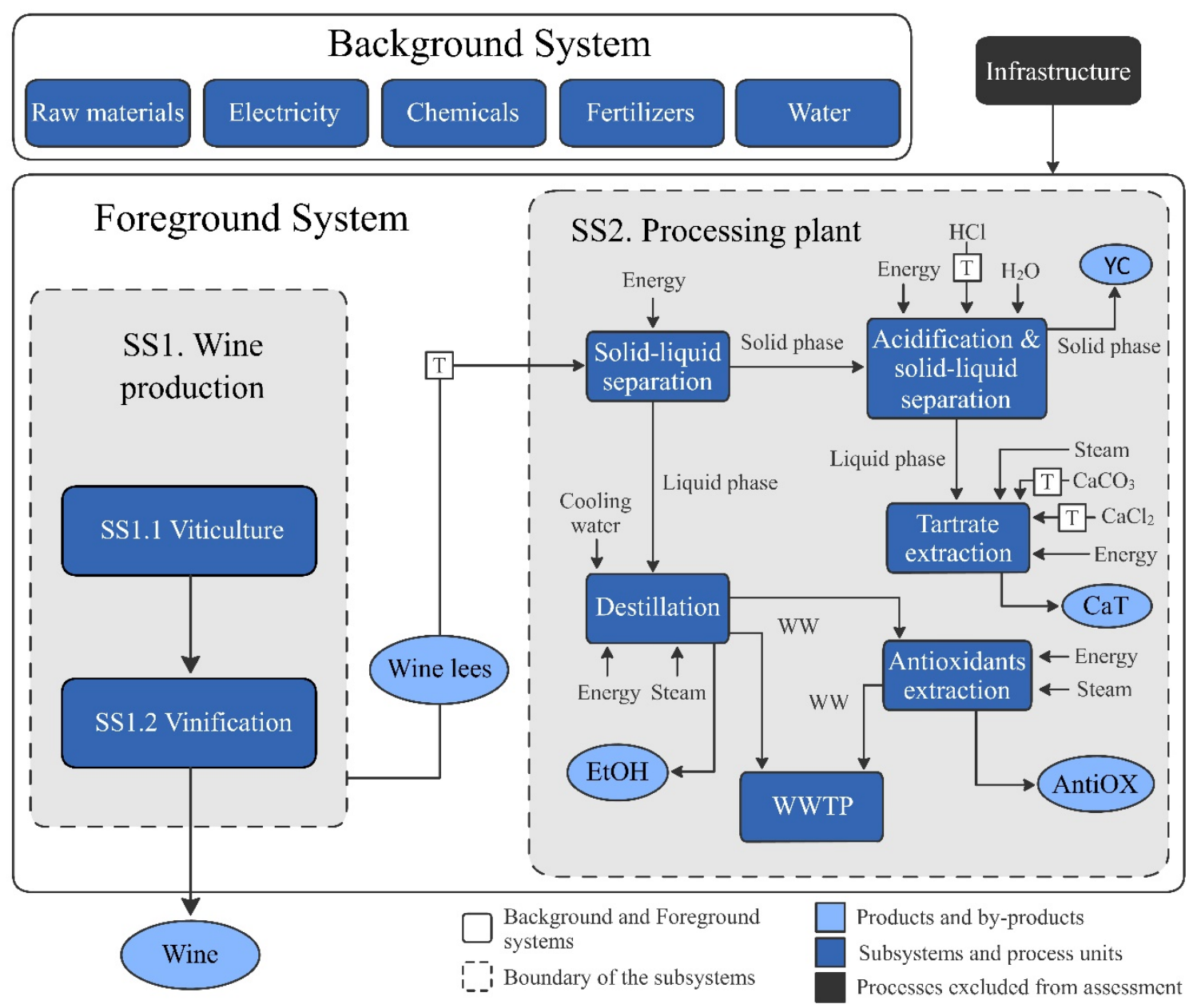


Figure 1. System boundaries of the wine lees biorefinery to produce value-added products. Caption: T: Transport; EtOH: Bioethanol; CaT: Calcium tartrate; YC: Yeast cells; AntiOX: Antioxidants; WW: Wastewater; WWTP: Wastewater Treatment Plant

Subsystem 2 is the industrial process in which wine lees are valorized to produce four end-products, in this case bioethanol, calcium tartrate, an extract rich in antioxidants and solid fraction rich in protein, which can be marketed with an economic return. The description of the stages of the valorization process is described below. The first step is the separation of the liquid and solid fractions by centrifugation of the wine lees in a disc centrifuge. Wine lees fed the facilities at room temperature $\left(25^{\circ} \mathrm{C}\right)$ and with a content of 62.9\% (w/w) water, 5.7\% (w/w) ethanol and 31.4\% (w/w) solids (Dimou et al., 2016). It is possible to recover the residual fraction of ethanol present in the liquid fraction by distillation at $100^{\circ} \mathrm{C}$. In this step, the product stream of the bottom contains mainly water and is sent to treatment. The solid fraction is then sent to an extraction tank in which it is mixed with the ethanol recovered in the previous stage. The recovery of ethanol implies a significant reduction in the cost associated with this stage since it is available in the original wine lees (Dimou et al., 2016). A new solid-liquid separation is then carried out in a disc centrifuge so that the liquid fraction is fed to another distillation column in which the antioxidant-rich extract is separated as a bottom product. The removal of water from this stream takes place in an evaporator and in a spray dryer which works with high pressure steam. The solid stream from the second solid-liquid separation is mixed with $\mathrm{HCl}$ and the tartrate salt (insoluble in water) is transformed into tartaric acid (water-soluble). This compound is mixed with calcium carbonate $\left(\mathrm{CaCO}_{3}\right)$ and calcium chloride $\left(\mathrm{CaCl}_{2}\right)$, transforming water-soluble tartaric acid into water-insoluble calcium tartrate. Calcium tartrate is obtained as a solid product 
after the drying stage. Yeast cells are also obtained from the solid fraction, which can be marketable as animal feed to obtain an economic return.

\subsection{Data acquisition}

The data used in this study come from complementary studies that consider all stages of the life cycle of wine production, which includes the vine cultivation and the winery processing stage (Subsystem 1) to the valorization of the different fractions of wine and its by-products within the biorefinery (Subsystem 2) with a processing capacity of 500 $\mathrm{kg} / \mathrm{h}$ of wine lees developed in Dimou et al. (2016). An environmental assessment was carried out with a common perspective defined on the basis of an identical functional unit for both subsystems: 1 tonne of wine lees. The inventory data for the production of all system inputs from background processes were taken from the Ecoinvent ${ }^{\circledR}$ database. These inputs include the production of the different chemical products necessary for the extraction of calcium tartrate, the electricity consumed in the different stages, the fertilizers for the vine cultivation and any other type of raw material or resource. An average transport distance of $800 \mathrm{~km}$ was considered within continental Europe for chemical products (Pérez-López et al., 2014b) and 100 km of average distance for the transport of the wine lees from the winery to the processing plant were assumed (Hajjaji et al., 2013).

\subsection{Life cycle inventory}

The life cycle inventory is the compilation of the data set for evaluation and involves the collection of quantitative input/output data for the system. In this study, a cradle-togate approach has been proposed, taking into account all stages, from the cultivation of the vine to the activities of the winery and the valorisation of the wine lees. Considering that the economic allocation reflects the function and objective of the production 
process, which is obviously the marketing of a main product: wine and the associated economic revenues, mass or energy-based allocations were discarded (Rugani et al., 2013). Since wine lees are a residue derived from the production of wine, it is necessary to make a cost estimate as a requirement for an economic allocation that allows the environmental impacts corresponding to each fraction to be assessed. Thus, the selling price of a bottle of wine produced after SS1 was compared with the potential selling price of the various products obtained from the valorisation route (extract rich in antioxidants, ethanol, yeast cells and calcium tartrate). A market prize of $€ 4$ for a 750 $\mathrm{mL}$ bottle of wine with designation of origin was considered. Considering that the production of a bottle of this wine generates $11.48 \mathrm{ml}$ of wine lees, the sale of these products generates a profit of $€ 0.022$ and when comparing the contributions of both products in terms of their market value, the economic allocation factors are $99.45 \%$ for wine and $0.55 \%$ for wine lees.

\subsection{Life cycle impact assessment: methodology}

SimaPro 8.5.2 (PRé Consultants, 2017) has been the software used for the implementation of the Life Cycle Inventory. To analyze the inputs and outputs of the LCI, the Classification and Characterization guidelines defined by ISO were followed. In this phase, in order to translate the long list of life cycle inventory results into a small number of environmental impact indicators, the ReCiPe Midpoint methodology was used. This method provides a common framework in which both mid-point and endpoint indicators can be used (Goedkoop et al., 2009). The characterization factors reported by the ReCiPe Midpoint methodology were applied, and the potential impact categories considered were: Climate Change, Ozone Layer Depletion, Terrestrial Acidification, Freshwater Eutrophication, Marine Eutrophication, Human Toxicity, 

Marine Ecotoxicity and Fossil Fuel Depletion.

\section{Results and discussion}

\subsection{Quantitative analysis of inputs and outputs to the overall system}

216

217

Life Cycle Assessment is a structured and comprehensive method for quantifying material and energy flows and associated impacts on the life cycle of products (i.e. goods and services). Within the LCA methodology, Life Cycle Inventory is a mandatory stage and the availability of LCI data is often the greatest barrier to completing an LCA study.

LCI shows that the consumption of different pesticides is very high in the viticulture stage, which is in line with other studies on different crops (Caldeira et al., 2018; Liang et al., 2019). In addition, the consumption of organic fertilizers is also remarkable, leading to relevant nitrate emissions, so the impact on the eutrophication categories is expected to be considerable. As for the winemaking phase, the main inputs are electricity and chemicals such as $\mathrm{NaOH}$ and $\mathrm{SO}_{2}$. In this system, $\mathrm{CO}_{2}$ emissions due to wine fermentation were calculated, but excluded from the environmental assessment, as biogenic $\mathrm{CO}_{2}$ at this stage was not taken into account. LCI has also allowed to quantify the main inputs and outputs of the wine lees valorization system, highlighting the consumption of High-Pressure Steam and the production of four value-added products.

The main product obtained in this process is the extract rich in antioxidants. This extract, as calculated in Dimou et al. (2016), has a lower total polyphenol content than other studies (26.1 mg of gallic acid equivalent per g of wine lees). Therefore, this extraction is not optimized, and the product could be purer. However, wine lees 
valorization can be considered as a sustainable and environmentally friendly process due to the fact that most of the operations carried out are physical, such as solid-liquid extraction or centrifugation, while other studies involve complex operations, such as ultrasound or microwave assisted extraction (Castro-López et al., 2017;

Mohammadpour et al., 2019; Pereira et al., 2017). Since most of the treatments carried out at this stage are physical, the use of chemical products is low, as only $174 \mathrm{~kg}$ per ton of treated wine lees are consumed. Further details of Life Cycle Inventory are provided in electronic Supplementary data.

\subsection{Analysis of processing plant energy requirements}

Electricity and steam consumption reported in supplementary material correspond to the operation of the plant and is broken down by equipment in Table 1. Although the total electricity consumption is not too high (125 kWh per FU), more than 95\% of this consumption corresponds to disc centrifuges, which are used to separate the solid phase from the liquid phase. This separation process is essential to obtain value-added products, as most of the treatments carried out are physical, such as stages of distillation, separation, evaporation and spray drying with compressed hot air.

Steam consumption is very high, more than 5 tons of steam per ton of wine lees treated. In the process, steam is used in distillation columns (units E-102 and E-104) while in the unit E-105, steam is used to evaporate water from the antioxidant-rich stream. Finally, in the E-106 and E-107 exchangers, steam is used to heat the compressed air that will be used in the spray dryers to remove the remaining water from the calcium tartrate and the antioxidant-rich extract. This consumption, together with the fact that obtaining steam is an activity with high energy requirements (Nieuwlaar et al., 2015), 
258 makes it possible to anticipate that the environmental impact derived from the use of

259 steam will be high.

260 
261 Table 1. Analysis of the electricity, steam and cooling water consumption of Subsystem 262 2. Processing plant per FU (1 tonne of wine lees)

\begin{tabular}{cccc}
\hline Operation & $\begin{array}{c}\text { Electricity } \\
\text { consumption (kWh) }\end{array}$ & $\begin{array}{c}\text { Steam } \\
\text { consumption } \mathbf{( k g )}\end{array}$ & $\begin{array}{c}\text { Cooling water } \\
\left(\mathbf{m}^{\mathbf{3}}\right)\end{array}$ \\
\hline Disc centrifuges & $\mathbf{1 1 9 . 1 9}$ & & \\
CF-101 & 29.80 & & \\
CF-102 & 29.80 & & \\
CF-103 & 29.80 & & \\
CF-104 & 29.79 & & \\
Mixing tanks & $\mathbf{4 . 6 8}$ & & \\
V-101 & 2.60 & & $\mathbf{2 2 4 . 4 6}$ \\
V-102 & 1.20 & & \\
V-103 & 0.88 & & \\
Blower & $\mathbf{6 . 0 6}$ & & \\
C-101 & 4.06 & $\mathbf{5 1 0 4 . 8 4}$ & \\
C-102 & 2.00 & 819.44 & \\
Heat exchangers & & 3994.44 & \\
E-102 & & & \\
E-104 & & & \\
E-105 & & & \\
E-106 & & & \\
E-107 & & & \\
E-101 & & & \\
E-103 & & & \\
\hline
\end{tabular}

\subsection{Environmental characterization of wine lees valorization process}

The environmental impacts expressed through different impact categories are presented in the characterization stage, these results are summarized in Table 2. Figure 2 presents the contributions relative to the environmental burdens of each subsystem considered, identifying the most problematic ones with the greatest environmental impacts in the process of valorisation of wine lees. Specifically, in Subsystem 1, wine production is the main contributor to the categories of MET, FET, POF, HT, ME and TA. In MET and TET, SS1 represents almost $90 \%$ of the total environmental impact, which is related to the treatment of solid waste produced during winemaking. SS1.1 includes different 
273 activities of the agricultural phase of wine production such as soil management, field

274 operations or fertilisation. This phase is clearly the hotspot in ME, POF and TA

275 categories with remarkable contributions of $67.9 \%, 56.8 \%$ and $52.7 \%$ respectively. It

276 should be noted here that the use of fossil fuels for the operation of machinery such as

277 broadcasters and rotary cultivators and the use of compost for fertilization cause

278 emissions of nitrogen oxides that affect POF category. As for the environmental impacts

279 of ME, the application of fertilizers in the agricultural phase of wine production

280 involved the greatest relative impact of this category. These results are in accordance

281 with the results obtained in another study in which an LCA of red wine production from

282 Catalonia was performed (Meneses et al., 2016). This study showed that the vinification

283 process has a better environmental profile than the viticulture stage. Regarding HT

category, there are no major differences between the two considered subsystems

285

because the main contributors to the environmental impact in this category are the

286

emissions of heavy metals into the atmosphere derived from the consumption of fossil

287 fuels for the operation of equipment, transport and steam production.

Table 2. Impact assessment results associated with the valorization of 1 tonne of wine lees

\begin{tabular}{llcccc}
\hline Impact category & Unit & SS1.1 & SS1.2 & SS2 & Total \\
\hline CC & kg CO 2 eq & $8.79 \cdot 10^{2}$ & $3.26 \cdot 10^{2}$ & $1.33 \cdot 10^{3}$ & $2.54 \cdot 10^{3}$ \\
OD & kg CFC-11 eq & $1.14 \cdot 10^{-4}$ & $2.09 \cdot 10^{-5}$ & $1.52 \cdot 10^{-4}$ & $2.87 \cdot 10^{-4}$ \\
TA & kg SO 2 eq & 6.52 & 1.00 & 4.85 & 12.37 \\
FE & kg P eq & 0.15 & 0.05 & 0.22 & 0.42 \\
ME & kg N eq & 2.52 & 1.05 & 0.14 & 3.72 \\
HT & kg 1,4-DB eq & $1.85 \cdot 10^{2}$ & $1.86 \cdot 10^{2}$ & $2.43 \cdot 10^{2}$ & $6.14 \cdot 10^{2}$ \\
POF & kg NMVOC & 4.25 & 0.68 & 2.56 & 7.48 \\
TET & kg 1,4-DB eq & $3.67 \cdot 10^{-2}$ & $8.61 \cdot 10^{-3}$ & $1.08 \cdot 10^{-1}$ & $1.53 \cdot 10^{-1}$ \\
FET & kg 1,4-DB eq & 5.36 & 57.81 & 7.73 & 70.88 \\
MET & kg 1,4-DB eq & 5.25 & 49.77 & 7.01 & 62.03 \\
FD & kg oil eq & $1.10 \cdot 10^{2}$ & 46.85 & $4.35 \cdot 10^{2}$ & $5.92 \cdot 10^{2}$ \\
\hline
\end{tabular}


In relation to subsystem 2, the processing plant is the main contributor in FD and TET impact categories. In the FD category it reaches a maximum contribution of 75\% associated with the use of natural gas for steam production. In the TET category, it accounts for $70 \%$ of the impact due to emissions of heavy metals into the atmosphere linked to the use of fossil fuels, either in transport or in the production of high temperature steam. However, regarding FE, OD and CC categories, the difference between the two subsystems is minimal. Focusing on CC, direct emissions into the atmosphere associated with fermentation process are quantified in the winemaking process. However, direct $\mathrm{CO}_{2}$ emissions from SS1 should not be considered as fossil carbon, but as biogenic $\mathrm{CO}_{2}$. If these emissions were considered as fossil carbon, SS1 value of $2570 \mathrm{~kg}$ of $\mathrm{CO}_{2}$ eq per ton of wine lees.

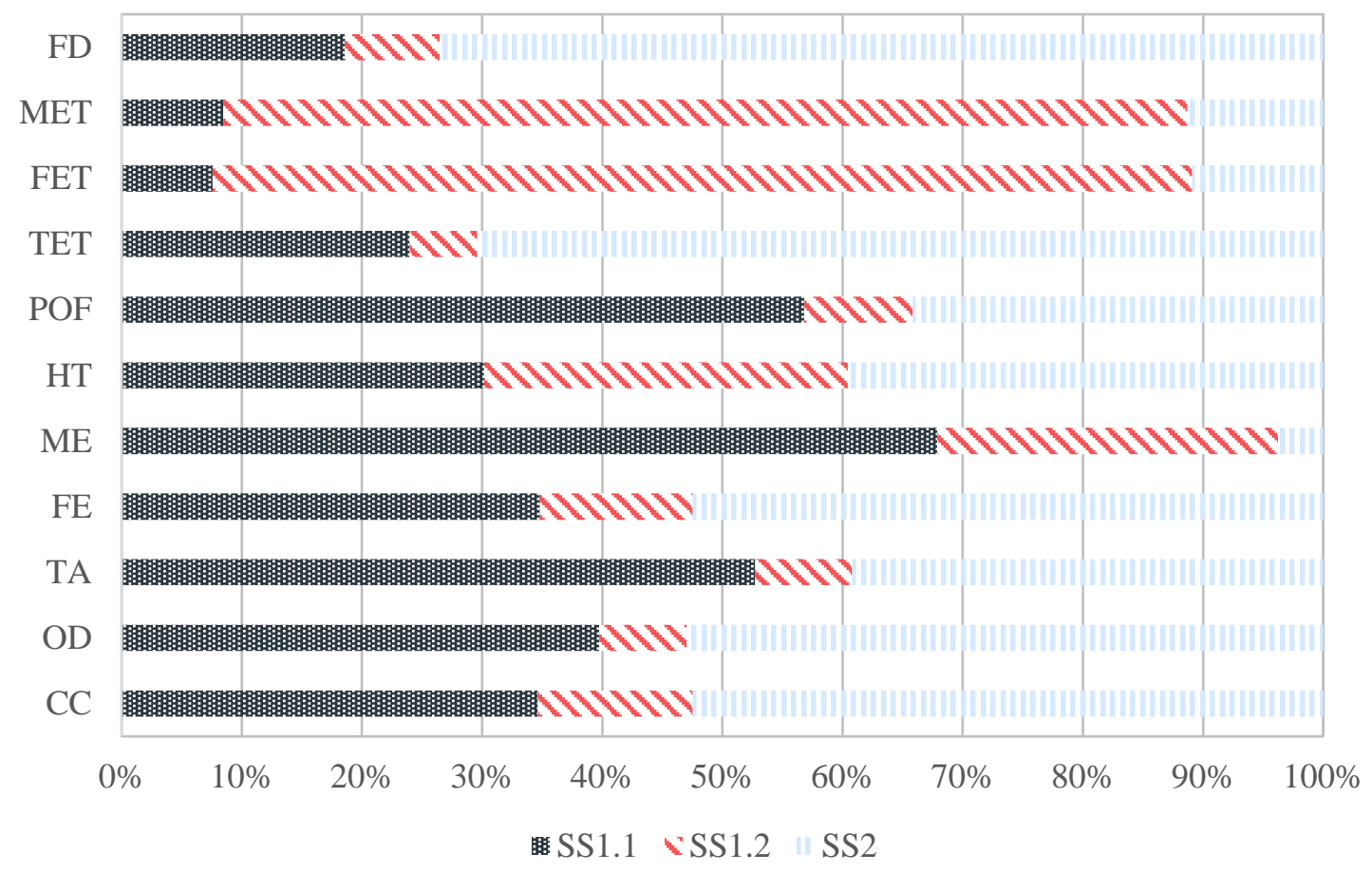

Figure 2. Relative contributions (in \%) by subsystems in the valorization of wine lees 
Taking into account the economic allocation factors calculated in Section 2.3, the characterisation results of the wine lees biorefinery were calculated (Figure 3).

According to the results obtained, wine lees can be classified as a winery waste that is not assigned an associated environmental impact. On the contrary, the use of high temperature steam can be considered as the most burdensome component. In this sense, the other categories include FD (85.7\%), CC (85.3\%), TA (79.4\%) and POF (76.7\%), all of which are associated with the high consumption of fossil fuels for the production of steam as well as the associated emissions of GHG, $\mathrm{SO}_{2}$ and NOx.

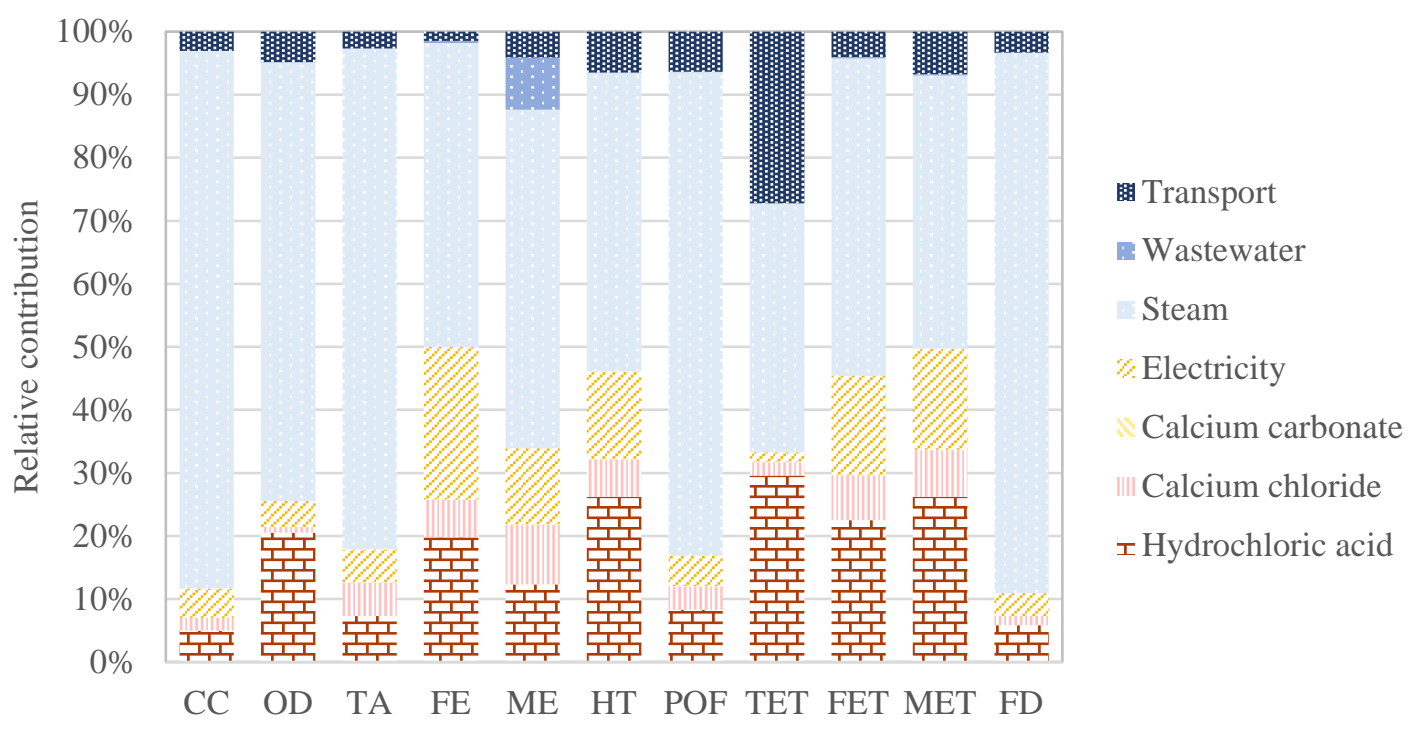

Figure 3. Relative contributions (in \%) by component in the overall biorefinery production process

Electricity has a low impact in almost all impact categories, which is attributed to a lowmoderate consumption (Table 1). Only FET shows a remarkable value of $24.2 \%$. $\mathrm{HCl}$ becomes the second most contributing element with an average of $16.7 \%$, standing out in the categories of toxicity, either Human (HT) or Ecosystem (TET, MET and FET); due to emissions of heavy metals associated with the production of $\mathrm{HCl}, \mathrm{H}_{2} \mathrm{SO}_{4}$ and $\mathrm{Cl}_{2}$ compounds. In contrast, the impact of $\mathrm{CaCl}_{2}$ and $\mathrm{CaCO}_{3}$ are of much lesser importance 
with average contributions of $4.7 \%$ and $0.03 \%$ respectively. Transport presents a considerably uniform distribution of environmental impacts in all categories, with contributions almost always lower than 7\%, except in the case of the TET category, in which a relative contribution of around $27.2 \%$ is reached. This is because this category gives more weight to emissions to air and soil (which are abundant in transport processes); in contrast, other toxicity categories such as MET and FET are more dependent on water emissions, with negligible impacts. Wastewater treatment contributions are practically negligible except for a percentage of 8.2\% in ME category, due to nitrogen compounds directly discharged into the water.

\subsection{Sensitivity analysis. Effect of the selection of the Functional Unit and allocation} factors on the environmental profile

The results obtained are based on a FU that focuses on the amount of biomass valorized rather than on the products obtained. In fact, the choice of FU is a critical point in any LCA study as it is a subjective action that must be consistent with the objectives of the study. In this case the function of the system is the treatment of a waste, but this system allows to obtain four different products. The extract rich in antioxidants is the product of greatest interest for its potential applications in the food industry, cosmetics and pharmaceutical industry (Szabo et al., 2018). Therefore, the new FU was selected as 1 $\mathrm{kg}$ of antioxidant-rich extract obtained.

In addition to the choice of the FU, the allocation of impacts is fundamental, especially in multi-production processes such as the one studied here. If a mass or economic allocation is followed, the impacts assigned to each product are different. Therefore, the factors of mass and economic allocation have been calculated by the quantity produced 
of each element and its potential market price obtained from various scientific publications. A summary of the considered allocation factors is given in Table 3 .

Table 3. Computation of the mass and economic allocation factors for SS2. Processing plant

\begin{tabular}{lcccc}
\hline Product & Production $^{\mathrm{a}}$ & Market price & $\begin{array}{c}\text { Mass } \\
\text { allocation }\end{array}$ & $\begin{array}{c}\text { Economic } \\
\text { allocaion }\end{array}$ \\
\hline Bioethanol & $28.22 \mathrm{~kg}$ & $0.67 € / \mathrm{kg}^{\mathrm{b}}$ & $8.4 \%$ & $1.3 \%$ \\
Calcium tartrate & $58.50 \mathrm{~kg}$ & $4.41 € / \mathrm{kg}^{\mathrm{c}}$ & $17.5 \%$ & $17.3 \%$ \\
Yeast cells & $241.00 \mathrm{~kg}$ & $0.88 € / \mathrm{kg}^{\mathrm{c}}$ & $72.0 \%$ & $14.2 \%$ \\
Antioxidants & $6.78 \mathrm{~kg}$ & $147.67 € / \mathrm{kg}^{\mathrm{d}}$ & $2.0 \%$ & $67.6 \%$ \\
\hline
\end{tabular}

${ }^{a}$ Results per Functional unit (1 tonne of wine lees)

b (Joelsson et al., 2016)

c (Dimou et al., 2016)

d (Vieira et al., 2013)

These studies show how the market prices of each of the products obtained in the biorefinery varies and how the mass and economic allocations factors vary accordingly. Joelsson et al. (2016) conducted a research on the production of biogas and bioethanol from wheat straw impregnated with acetic acid. In addition to the experimental study, they also performed a techno-economic evaluation. In this paper a bioethanol price of 0.57-0.68 €/kg is estimated. In Dimou et al. (2016) a techno-economic evaluation of the biorefinery which is environmentally evaluated in the present study was carried out and a market cost for yeast cells of $1 \$ / \mathrm{kg}$ was estimated. This price can be converted to euros and is equivalent to $0.88 € / \mathrm{kg}$. Finally, in Vieira et al (2013) a chemical and economic evaluation of antioxidants extracted from pulp of Euterpe edulis was carried out. The manufacturing costs of the crude extracts obtained in this paper were 165.34 $\$ / \mathrm{kg}$, which is equivalent to $147.67 € / \mathrm{kg}$. These manufacturing costs were assumed as the market cost of this extract in order to obtain an economic return.

The effect of the alternative FU and allocation factors on the environmental profiles is shown in Table 4. When allocation factors (mass or economic) are used, a decrease in 


\begin{tabular}{llccc}
\hline $\begin{array}{l}\text { Impact } \\
\text { category }\end{array}$ & Units & No allocation & $\begin{array}{c}\text { Mass } \\
\text { allocation }\end{array}$ & $\begin{array}{c}\text { Economic } \\
\text { allocation }\end{array}$ \\
\hline CC & kg CO 2 eq & 374.1 & 7.6 & 251.3 \\
OD & kg CFC-11 & $4.2 \cdot 10^{-5}$ & $8.6 \cdot 10^{-7}$ & $2.8 \cdot 10^{-5}$ \\
TA & eq & & & \\
FE & kg SO 2 eq & 1.8 & $3.7 \cdot 10^{-2}$ & 1.2 \\
ME & kg P eq & $6.2 \cdot 10^{-2}$ & $1.3 \cdot 10^{-3}$ & $4.2 \cdot 10^{-2}$ \\
HT & kg N eq & $5.5 \cdot 10^{-1}$ & $1.1 \cdot 10^{-2}$ & $3.7 \cdot 10^{-1}$ \\
POF & kg 1,4-DB eq & 90.6 & 1.8 & 60.9 \\
TET & kg NMVOC & 1.1 & $2.2 \cdot 10^{-2}$ & $7.4 \cdot 10^{-1}$ \\
FET & kg 1,4-DB eq & $2.3 \cdot 10^{-2}$ & $4.6 \cdot 10^{-4}$ & $1.5 \cdot 10^{-2}$ \\
MET & kg 1,4-DB eq & 10.4 & $2.1 \cdot 10^{-1}$ & 7.0 \\
FD & kg 1,4-DB eq & 9.1 & $1.9 \cdot 10^{-1}$ & 6,15 \\
\hline
\end{tabular}

379 the basis of an identical FU: $1 \mathrm{~kg}$ of extract rich in antioxidants and evaluation 
methodology: CLM. Pérez-López et al. (2014a) evaluated the environmental performance of several Sargassum muticum macroalgae valorization strategies. In this study it was considered that the combined extraction of antioxidants and alginates stands out as the most sustainable scenario. Pérez-López et al. (2014b) conducted a life cycle assessment of astaxanthin production on a laboratory and pilot scale. In Papadaki et al. (2017) an evaluation of the life cycle of the recovery of phycocyanin from Spirulina platensis cyanobacterium is performed. This study compares six different methods based on Ultrasound-Assisted Extraction to recover phycocyanin. In order to simplify the comparative study, the results are scaled to 100 and represented in Figure 4.
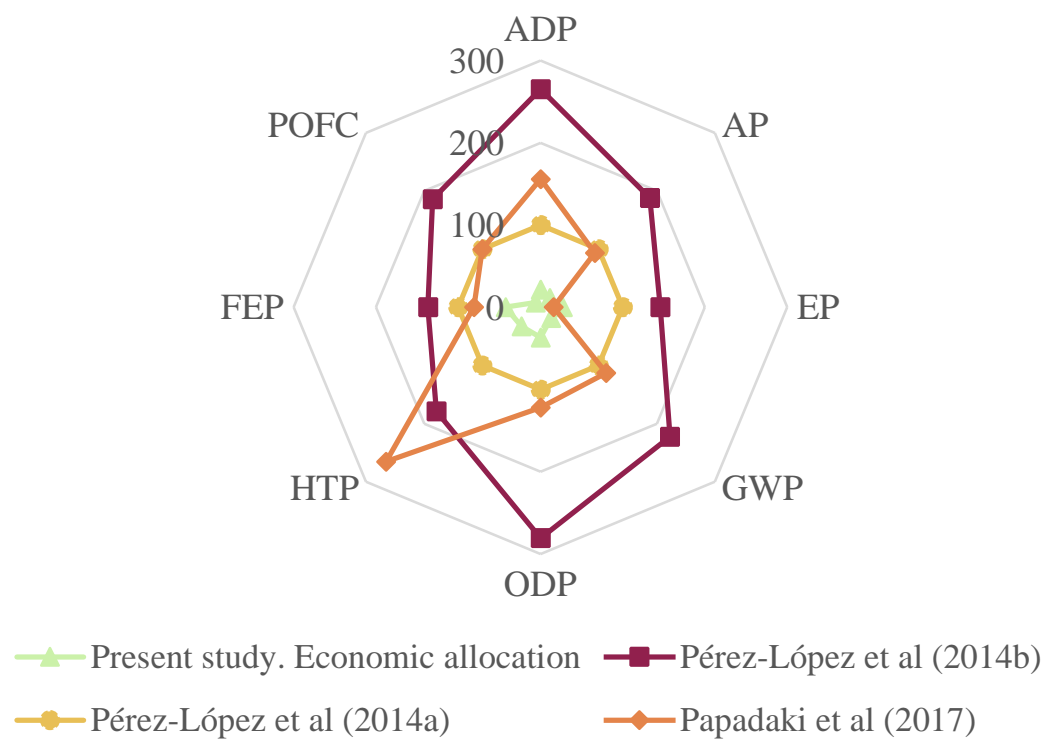

Figure 4. Relative environmental profile of the compared valorization scenarios with the process published in (Pérez-López et al., 2014a) as baseline (index = 100)

According to the results depicted in Figure 4, the production of antioxidants through the valorization of wine lees would be the most appropriate route in all the impact categories studied. Except in the case of EP, where the recovery of phycocyanin from a cyanobacterium is the process with the best environmental profile, since the impacts of 
401 EP are directly related to emissions linked to fertilization in the viticulture phase. The

402

403

404

405

406

407

408

409

410 production of astaxanthin from microalgae cultivated in photobioreactors on a pilot scale reported the worst environmental profile, with results ranging from 37\% worse than the reference (index $=100$ ) in FEP category up to 180\% worse in ODP impact category. If the present study is compared with the process published by Pérez-López et al. (2014a), the production of antioxidants from the treatment of wine lees presents an environmental profile that is, on average, $75 \%$ better in all impact categories. A maximum improvement rate of $92 \%$ is reached in the FEP impact category. However, in order to obtain $1 \mathrm{~kg}$ of extract rich in antioxidants, it is necessary to treat almost $148 \mathrm{~kg}$ of wine lees, while in order to obtain this same amount of extract from the valorization of Sargassum muticum, it is only necessary to process $1.5 \mathrm{~kg}$ of biomass. In particular, the treatment of wine lees has better environmental results because most of the operations performed are physical (solid/liquid separations, distillations, evaporations, etc.) and do not involve the large consumption of electricity or chemicals. There is only one determinant consumption in the system, the high temperature steam, while in the rest of the comparative studies, the consumption of electricity and chemicals is relatively high. Comparative analysis has allowed us to compare the valorization of wine lees with others related to the production of antioxidants from different raw materials published in the scientific literature. The valorization of wine lees presents the best environmental profile in almost all compared categories.

\section{Conclusions}

Nowadays special interest is being paid into the valorization of different wastes in order to reduce raw materials consumption. Thus, it has been shown that the integral valorization of wine lees is a very attractive process to produce value-added products. Winemaking is a process with a high demand for chemicals, which leads to a high 
environmental impact. Therefore, this system causes $50 \%$ of the total impact of wine lees valorization. However, on a comparative level with other processes in which an antioxidant-rich extract can be obtained, it has been demonstrated that the valorization of wine lees presents the best environmental profile throughout the entire life cycle in almost all the impact categories studied. However, steam consumption has proven to be an important hotspot in the process, so it will be necessary to reduce this consumption in the future. In order to achieve this objective, other residues from the winery, such as grape stalks, could be used as raw material to obtain high temperature steam in a boiler.

Wine waste biorefining is an appropriate way of obtaining products from waste according to the principles of the Circular Economy, where waste is converted into new raw materials. This work shows that the LCA methodology is a useful tool for assessing the environmental impact of wine lees treatment in order to obtain value-added products. The results of this work should be considered in order to develop a more sustainable way of obtaining an antioxidant-rich extract from agricultural residues.

\section{Acknowledgements}

This research was supported by the European Project STAR-ProBio (Grant Agreement Number 727740). The authors belong to the Galician Competitive Research Group GRC ED431C 2017/2019 and to the CRETUS Strategic Partnership (ED431E 2018/01). All these programmes are co-funded by FEDER (EU).

\section{References}

Algapani, D.E., Qiao, W., Ricci, M., Bianchi, D., Wandera, S.M., Adani, F., Dong, R., 2019. Bio-hydrogen and bio-methane production from food waste in a two-stage anaerobic digestion process with digestate recirculation. Renew. Energy 130, 
450

Caldeira, C., Quinteiro, P., Castanheira, E., Boulay, A., Dias, A.C., Arroja, L., Freire, F., 2018. Water footprint profile of crop-based vegetable oils and waste cooking oil: Comparing two water scarcity footprint methods. J. Clean. Prod. 195, 1190 1202. https://doi.org/10.1016/j.jclepro.2018.05.221

Castro-López, C., Ventura-Sobrevilla, J.M., González-Hernández, M.D., Rojas, R., Ascacio-Valdés, J.A., Aguilar, C.N., Martínez-Ávila, G.C.G., 2017. Impact of extraction techniques on antioxidant capacities and phytochemical composition of polyphenol-rich extracts. Food Chem. 237, 1139-1148. https://doi.org/10.1016/j.foodchem.2017.06.032

Cherubini, F., 2010. The biorefinery concept: Using biomass instead of oil for producing energy and chemicals. Energy Convers. Manag. 51, 1412-1421. https://doi.org/10.1016/j.enconman.2010.01.015

Christ, K.L., Burritt, R.L., 2013. Critical environmental concerns in wine production: An integrative review. J. Clean. Prod. 53, 232-242. https://doi.org/10.1016/j.jclepro.2013.04.007

Devesa-Rey, R., Vecino, X., Varela-Alende, J.L., Barral, M.T., Cruz, J.M., Moldes, A.B., 2011. Valorization of winery waste vs. the costs of not recycling. Waste Manag. 31, 2327-2335. https://doi.org/10.1016/j.wasman.2011.06.001

Dimou, C., Kopsahelis, N., Papadaki, A., Papanikolaou, S., Kookos, I.K., Mandala, I., Koutinas, A.A., 2015. Wine lees valorization: Biorefinery development including production of a generic fermentation feedstock employed for poly(3hydroxybutyrate) synthesis. Food Res. Int. 73, 81-87. https://doi.org/10.1016/j.foodres.2015.02.020 
Dimou, C., Vlysidis, A., Kopsahelis, N., Papanikolaou, S., Koutinas, A.A., Kookos, I.K., 2016. Techno-economic evaluation of wine lees refining for the production of value-added products. Biochem. Eng. J. 116, 157-165. https://doi.org/10.1016/j.bej.2016.09.004

Escribano-Viana, R., Portu, J., Garijo, P., Gutiérrez, A.R., Santamaría, P., LópezAlfaro, I., López, R., González-Arenzana, L., 2018. Evaluating a preventive biological control agent applied on grapevines against Botrytis cinerea and its influence on winemaking. J. Sci. Food Agric. 98, 4517-4526. https://doi.org/10.1002/jsfa.8977

European Comission, 2011. A Roadmap for moving to a competitive low carbon economy in 2050.

FAO, 2011. Global food losses and food waste - Extent, causes and prevention. Rome.

García-Herrera, P., Sánchez-Mata, M.C., Cámara, M., 2010. Nutritional characterization of tomato fiber as a useful ingredient for food industry. Innov. Food Sci. Emerg. Technol. 11, 707-711. https://doi.org/10.1016/j.ifset.2010.07.005

Goedkoop, M., Heijungs, R., Huijbrets, M., de Schryver, A., Struijs, J., Van Zelm, R., 2009. ReCiPe 2008: A life cycle impact assessment method which comprises harmonised category indicators at the midpoint and the endpoint level. Report I: Characterisation.

Gullón, P., Gullón, B., Dávila, I., Labidi, J., González-García, S., 2018. Comparative environmental Life Cycle Assessment of integral revalorization of vine shoots from a biorefinery perspective. Sci. Total Environ. 624, 225-240. https://doi.org/10.1016/j.scitotenv.2017.12.036 
Hajjaji, N., Pons, M.N., Renaudin, V., Houas, A., 2013. Comparative life cycle assessment of eight alternatives for hydrogen production from renewable and fossil feedstock. J. Clean. Prod. 44, 177-189. https://doi.org/10.1016/j.jclepro.2012.11.043

ISO, 2006a. ISO 14040 - Environmental Management - Life Cycle Assessment Principles and Framework. International Organization for Standardization.

ISO, 2006b. ISO 14044 - Environmental Management - Life Cycle Assessment Requirements and Guidelines. International Organization for Standardization.

Jeswani, H.K., Falano, T., Azapagic, A., 2015. Life cycle environmental sustainability of lignocellulosic ethanol produced in integrated thermo-chemical biorefineries. Biofuels, Bioprod. Biorefining 9, 661-676. https://doi.org/10.1002/bbb

Joelsson, E., Dienes, D., Kovacs, K., Galbe, M., Wallberg, O., 2016. Combined production of biogas and ethanol at high solids loading from wheat straw impregnated with acetic acid: experimental study and techno-economic evaluation. Sustain. Chem. Process. 4, 14. https://doi.org/10.1186/s40508-016-0058-5

Karlsson, H., Börjesson, P., Hansson, P.A., Ahlgren, S., 2014. Ethanol production in biorefineries using lignocellulosic feedstock - GHG performance, energy balance and implications of life cycle calculation methodology. J. Clean. Prod. 83, 420427. https://doi.org/10.1016/j.jclepro.2014.07.029

Khoshnevisan, B., Rafiee, S., Tabatabaei, M., Ghanavati, H., Mohtasebi, S.S., Rahimi, V., Shafiei, M., Angelidaki, I., Karimi, K., 2018. Life cycle assessment of castorbased biorefinery: a well to wheel LCA. Int. J. Life Cycle Assess. 23, 1788-1805. https://doi.org/10.1007/s11367-017-1383-y 
Kopsahelis, N., Dimou, C., Papadaki, A., Xenopoulos, E., Kyraleou, M., Kallithraka, S., Kotseridis, Y., Papanikolaou, S., Koutinas, A.A., 2018. Refining of wine lees and cheese whey for the production of microbial oil, polyphenol-rich extracts and value-added co-products. J. Chem. Technol. Biotechnol. 93, 257-268. https://doi.org/10.1002/jctb.5348

Lam, C.M., Yu, I.K.M., Hsu, S.C., Tsang, D.C.W., 2018. Life-cycle assessment on food waste valorisation to value-added products. J. Clean. Prod. 199, 840-848. https://doi.org/10.1016/j.jclepro.2018.07.199

Liang, L., Wang, Y., Ridoutt, B.G., Lal, R., Wang, D., Wu, W., Wang, L., Zhao, G., 2019. Agricultural subsidies assessment of cropping system from environmental and economic perspectives in North China based on LCA. Ecol. Indic. 96, 351360. https://doi.org/10.1016/j.ecolind.2018.09.017

Makkar, H.P.S., 2018. Review: Feed demand landscape and implications of food-not feed strategy for food security and climate change. Animal 12, 1744-1754. https://doi.org/10.1017/S175173111700324X

Martinez, G.A., Rebecchi, S., Decorti, D., Domingos, J.M.B., Natolino, A., Del Rio, D., Bertin, L., Da Porto, C., Fava, F., 2016. Towards multi-purpose biorefinery platforms for the valorisation of red grape pomace: production of polyphenols, volatile fatty acids, polyhydroxyalkanoates and biogas. Green Chem. 18, 261-270. https://doi.org/10.1039/c5gc01558h

Meneses, M., Torres, C.M., Castells, F., 2016. Sensitivity analysis in a life cycle assessment of an aged red wine production from Catalonia, Spain. Sci. Total Environ. 562, 571-579. https://doi.org/10.1016/j.scitotenv.2016.04.083

Mohammadpour, H., Sadrameli, S.M., Eslami, F., Asoodeh, A., 2019. Optimization of 
ultrasound-assisted extraction of Moringa peregrina oil with response surface methodology and comparison with Soxhlet method. Ind. Crops Prod. 131, 106116. https://doi.org/10.1016/j.indcrop.2019.01.030

Musee, N., Lorenzen, L., Aldrich, C., 2007. Cellar waste minimization in the wine industry: a systems approach. J. Clean. Prod. 15, 417-431. https://doi.org/10.1016/j.jclepro.2005.11.004

Nayak, A., Bhushan, B., Rodriguez-Turienzo, L., 2018. Recovery of polyphenols onto porous carbons developed from exhausted grape pomace: A sustainable approach for the treatment of wine wastewaters. Water Res. 145, 741-756. https://doi.org/10.1016/j.watres.2018.09.017

Nieuwlaar, E., Roes, A.L., Patel, M.K., 2015. Final energy requirements of steam for use in environmental life cycle assessment. J. Ind. Ecol. 20, 828-836. https://doi.org/10.1111/jiec.12300

OIV, 2018. State of the Vitiviniculture World Market, April 2018, International Organisation of Vine and Wine.

Papadaki, S., Kyriakopoulou, K., Tzovenis, I., Krokida, M., 2017. Environmental impact of phycocyanin recovery from Spirulina platensis cyanobacterium. Innov. Food Sci. Emerg. Technol. 44, 217-223. https://doi.org/10.1016/j.ifset.2017.02.014

Pereira, P., Cebola, M.J., Oliveira, M.C., Bernardo Gil, M.G., 2017. Antioxidant capacity and identification of bioactive compounds of Myrtus communis L. extract obtained by ultrasound-assisted extraction. J. Food Sci. Technol. 54, 4362-4369. https://doi.org/10.1007/s13197-017-2907-y 
Pérez-López, P., Balboa, E.M., González-García, S., Domínguez, H., Feijoo, G., Moreira, M.T., 2014a. Comparative environmental assessment of valorization strategies of the invasive macroalgae Sargassum muticum. Bioresour. Technol. 161, 137-148. https://doi.org/10.1016/j.biortech.2014.03.013

Pérez-López, P., González-García, S., Jeffryes, C., Agathos, S.N., McHugh, E., Walsh, D., Murray, P., Moane, S., Feijoo, G., Moreira, M.T., 2014b. Life cycle assessment of the production of the red antioxidant carotenoid astaxanthin by microalgae: from lab to pilot scale. J. Clean. Prod. 64, 332-344. https://doi.org/10.1016/j.jclepro.2013.07.011

Poveda, J.M., Loarce, L., Alarcón, M., Díaz-Maroto, M.C., Alañón, M.E., 2018. Revalorization of winery by-products as source of natural preservatives obtained by means of green extraction techniques. Ind. Crops Prod. 112, 617-625. https://doi.org/10.1016/j.indcrop.2017.12.063

PRé Consultants, 2017. SimaPro Database Manual (No. Methods Library). The Netherlands.

Roy, P., Nei, D., Orikasa, T., Xu, Q., Okadome, H., Nakamura, N., Shiina, T., 2009. A review of life cycle assessment (LCA) on some food products. J. Food Eng. 90, 110. https://doi.org/10.1016/j.jfoodeng.2008.06.016

Rugani, B., Vázquez-Rowe, I., Benedetto, G., Benetto, E., 2013. A comprehensive review of carbon footprint analysis as an extended environmental indicator in the wine sector. J. Clean. Prod. 54, 61-77. https://doi.org/10.1016/j.jclepro.2013.04.036

Ruggieri, L., Cadena, E., Martínez-Blanco, J., Gasol, C.M., Rieradevall, J., Gabarrell, X., Gea, T., Sort, X., Sánchez, A., 2009. Recovery of organic wastes in the Spanish 

wine industry. Technical, economic and environmental analyses of the composting process. J. Clean. Prod. 17, 830-838. https://doi.org/10.1016/j.jclepro.2008.12.005

Szabo, K., Cătoi, A.-F., Vodnar, D.C., 2018. Bioactive compounds extracted from tomato processing by-products as a source of valuable nutrients. Plant Foods Hum. Nutr. 73, 268-277. https://doi.org/10.1007/s11130-018-0691-0

United Nations, 2017. World population prospects: The 2017 Revision, key findings and advance tables.

Vandermeersch, T., Alvarenga, R.A.F., Ragaert, P., Dewulf, J., 2014. Environmental sustainability assessment of food waste valorization options. Resour. Conserv. Recycl. 87, 57-64. https://doi.org/10.1016/j.resconrec.2014.03.008

Vaskan, P., Pachón, E.R., Gnansounou, E., 2018. Techno-economic and life-cycle assessments of biorefineries based on palm empty fruit bunches in Brazil. J. Clean. Prod. 172, 3655-3668. https://doi.org/10.1016/j.jclepro.2017.07.218

Vázquez-Rowe, I., Villanueva-Rey, P., Moreira, M.T., Feijoo, G., 2012. Environmental analysis of Ribeiro wine from a timeline perspective: Harvest year matters when reporting environmental impacts. J. Environ. Manage. 98, 73-83. https://doi.org/10.1016/j.jenvman.2011.12.009

Vico, A., Pérez-Murcia, M.D., Bustamante, M.A., Agulló, E., Marhuenda-Egea, F.C., Sáez, J.A., Paredes, C., Pérez-Espinosa, A., Moral, R., 2018. Valorization of date palm (Phoenix dactylifera L.) pruning biomass by co-composting with urban and agri-food sludge. J. Environ. Manage. 226, 408-415. https://doi.org/10.1016/j.jenvman.2018.08.035

Vieira, G.S., Cavalcanti, R.N., Meireles, M.A.A., Hubinger, M.D., 2013. Chemical and 
economic evaluation of natural antioxidant extracts obtained by ultrasound-assisted and agitated bed extraction from jussara pulp (Euterpe edulis). J. Food Eng. 119, 196-204. https://doi.org/10.1016/j.jfoodeng.2013.05.030

Zabaniotou, A., Kamaterou, P., Pavlou, A., Panayiotou, C., 2018. Sustainable bioeconomy transitions: Targeting value capture by integrating pyrolysis in a winery waste biorefinery. J. Clean. Prod. 172, 3387-3397.

619 https://doi.org/10.1016/j.jclepro.2017.11.077

620

Zhang, N., Hoadley, A., Patel, J., Lim, S., Li, C., 2017. Sustainable options for the utilization of solid residues from wine production. Waste Manag. 60, 173-183.

622 https://doi.org/10.1016/j.wasman.2017.01.006

623 